\title{
Sintesis Kitosan-Lignin dengan Reaksi Mannich dan Karakterisasinya
}

\section{Synthesis of Chitosan-Lignin using Mannich Reaction and Its Characterization}

\author{
Nila Tanyela Berghuis*, M. Achyaruddin Wahid \\ Program Studi Kimia, Fakultas Sains dan Ilmu Komputer, Universitas Pertamina \\ *E-mail: nila.tanyela@universitaspertamina.ac.id \\ DOI : https://doi.org/10.26874/jkk.v4i1.77
}

Received: 1 April 2021, Revised: 30 May 2021, Accepted: 30 May 2021, Online: 31 May 2021

\begin{abstract}
Abstrak
Senyawa lignin dan kitosan merupakan biopolimer melimpah yang berada di alam. Akan tetapi aspek penggunaan dari biopolimer ini masih sangat minim dan hanya menjadi limbah di lingkungan. Sintesis lignin-kitosan dengan reaksi Mannich ini bisa menjadi salah satu alternatif untuk dapat menggunakan limbah tersebut hingga menjadi bahan yang berguna ke depannya. Kitosan yang digunakan merupakan kitosan komersil dengan \%DD (persen deasetilisasi) sebesar 71,57\%. Karakterisasi yang digunakan ialah FTIR serta TGA. Keberhasilan sintesis lignin-kitosan ditandai dengan munculnya peak pada spektrum FTIR pada bilangan gelombang $3300-3500 \mathrm{~cm}^{-1}$. Analisis TGA digunakan untuk mengetahui sifat degradasi termal dari senyawa lignin-kitosan yang diduga dapat menjadi senyawa biopolimer baru.
\end{abstract}

Kata kunci: Kitosan, Lignin, Reaksi Mannich

\begin{abstract}
Lignin and chitosan compounds are abundant biopolymers that occur in nature. However, the use aspect of this biopolymer is still very minimal and only becomes waste in the environment. The synthesis of lignin-chitosan using the Mannich reaction can be an alternative to be able to use this waste to become useful material in the future. The chitosan used was commercial chitosan with\% DD (percent deacetylation) of $71.57 \%$. The characterization used is FTIR and TGA. The success of lignin-chitosan synthesis is indicated by the appearance of peaks in the FTIR spectrum at wavenumbers 3300 - 3500 $\mathrm{cm}^{-1}$. TGA analysis is used to determine the thermal degradation properties of lignin-chitosan compounds which are thought to be new biopolymer compounds.
\end{abstract}

Keywords: Chitosan, Lignin, Mannich Reaction

\section{Pendahuluan}

Kitosan merupakan polimer alam yang berlimpah dan merupakan senyawa hasil deasetilasi dari senyawa kitin yang dapat ditemukan pada kulit Crustacea, terutama udang. Pemanfaatan kitosan sangat luas dikarenakan aspek karakteristik yang dimilikinya, diantaranya biodegradable, mudah untuk mengadsorpsi serta tidak beracun [1]. Di dalam kerangka struktur kitosan, terdapat gugus amina yang dapat dimanfaatkan sebagai sumber nukleofilik sehingga dapat membentuk ikatan dengan senyawa lain seperti lignin agar dapat menghasilkan senyawa turunannya yang diharapkan dapat meningkatkan pemanfaatan dari kitosan $[2,3]$.

Lignin merupakan polimer aromatik yang banyak di temukan di dalam tanaman yang berserat. Lignin sendiri merupakan senyawa pengikat selulosa dan hemiselulosa di dalam tanaman. Lignin memiliki tiga kerangka dasar (monomer) dalam bentuk p-coumaryl alcohol, coniferyl alcohol dan sinapyl alcohol [4]. Umumnya lignin diperoleh sebagai produk samping dari hasil pembuatan pulp dan biorefinery [5]. Adanya gugus seperti fenilpropana, 
fenolik hidroksil, dan karbonil mengindikasikan bahwa senyawa lignin memiliki sifat amfifilik, yaitu senyawa yang memiliki sifat hidrofilik (dapat mengikat air) dan lipofilik (dapat mengikat minyak). Lignin dapat digunakan sebagai bahan penguat [6], serat karbon [7], dan karbon aktif $[8,9]$. Walaupun memiliki sifat yang penting dan berguna, faktanya lignin hanya digunakan untuk memulihkan bahan kimia pembuatan pulp dengan cara dibakar dan menghasilkan pemanasan. Hal ini tentu saja sangat disayangkan mengingat banyak sifat penting yang dimiliki oleh lignin seperti biodegerdabilitas yang dapat dimanfaatkan salah satunya sebagai bahan dasar pembuatan plastik biodegradable [10]. Beberapa penelitian telah melakukan transformasi gugus fungsi terhadap lignin untuk meningkatkan aktivitasnya diantaranya adalah melalui reaksi aminase, sulfonasi dan alkilasi [11].

Reaksi aminasi adalah reaksi untuk menambahkan gugus amina pada suatu molekul [12]. Salah satu reaksi aminasi yang terkenal dan klasik ialah reaksi Mannich. Metode ini digunakan untuk pembuatan senyawa amino karbonil pada molekul sehingga dapat memberikan gugus amina pada molekul tersebut. Reaksi ini memiliki fleksibilitas dan potensi untuk menghasilkan keragaman fungsional dan struktural sehingga merangsang kreativitas para ahli kimia [13].

Dengan menggunakan reaksi Mannich, senyawa lignin-kitosan dapat disintesis dengan cara yang sederhana dan mudah dilakukan. Dengan terbentuknya lignin-kitosan, maka aplikasi dari lignin dan kitosan bertambah, dan tentu saja dapat meningkatkan nilai ekonomis dari kedua bahan tersebut. Saat ini, lignin-kitosan biasa dijadikan komposit untuk beberapa aplikasi seperti pembungkus makanan dan juga sebagai adsorben untuk membersihkan limbah tertentu seperti yang dilakukan oleh Nair dkk, mensintesis lignin-kitosan yang dimanfaatkan sebagai adsorben dyes [14].

\section{Metode Penelitian}

\subsection{Alat dan Bahan}

Alat-alat kimia yang digunakan dalam penelitian ini diantaranya adalah perlengkapan refluks, termometer $250^{\circ} \mathrm{C}$, hotplate tipe (Thermo Scientific), Oven (redLINE by BINDER), magnetic stirrer, corong Buchner, kertas $\mathrm{pH}$, kertas saring, spatula, batang pengaduk, tabung reaksi, vial, filler, alat gelas dengan merk (iwaki) dan (pyrex). Sedangkan bahan-bahan kimia yang digunakan ialah: lignin alkali $\mathrm{Mw} \sim 10.000$ (Sigma-Aldrich), kitosan komersil, formaldehid (MERCK KgaA),
$\mathrm{NaOH}$ teknis, $\mathrm{H}_{2} \mathrm{SO}_{4}$ p.a 95\% (MERCK KgaA), asam asetat p.a.

\subsection{Instrumentasi}

Instrumen untuk menguji sampel ligninkitosan yang digunakan: FTIR (Nicolet ${ }^{T M} i S^{T M}$ 5), spektrofotometer UV-Vis (Genesys 10S UV-VIS Spectrophotometer) dan TGA (SDT 650 Thermogravimetric Analysis).

\subsection{Cara Kerja}

\subsubsection{Sintesis Lignin-Kitosan}

Sebanyak 1,5 g lignin dilarutkan dalam 50 $\mathrm{ml}$ larutan asam asetat $2 \%$. Kemudian ditambahkan larutan $\mathrm{NaOH} 1 \mathrm{~N}$ hingga $\mathrm{pH}$ mencapai 11. Larutan tersebut direfluks didalam ruang asam hingga mencapai suhu $90^{\circ} \mathrm{C}$. Ketika suhu larutan lignin sudah mencapai $90^{\circ} \mathrm{C}$, ditambahkan formaldehid secara perlahan-lahan. Refluks dilakukan selama 4 jam. Setelah reaksi selesai, maka campuran reaksi kemudian didinginkan dan ditambahkan larutan asam sulfat $5 \mathrm{~N}$ hingga $\mathrm{pH}$ larutan mencapai 2. Padatan yang terbentuk kemudian disaring dengan corong Buchner dan dikeringkan dengan oven dengan suhu $55^{\circ} \mathrm{C}$ selama 12 jam atau semalaman hingga sampel kering.

\subsubsection{Karakterisasi Kitosan dan Lignin}

Karakterisasi yang dilakukan terhadap sampel lignin-kitosan diantaranya karakterisasi FTIR dengan plat $\mathrm{KBr}$, analisis $\mathrm{UV}-\mathrm{Vis}$ dan analisis TGA.

\section{$3 \quad$ Hasil dan Diskusi}

\subsection{Analisis Derajat Deasetilasi Kitosan \\ Komersil}

Sintesis lignin-kitosan dalam penelitian ini menggunakan bahan dasar kitosan komersil. Untuk melihat kualitas dari kitosan komersil yang digunakan pada penelitian ini, maka perlu dilakukan perhitungan derajat deasetilasi dengan menggunakan data spektrum FTIR. Persamaan rumus persen derajat deasetilasi (pers. 1) yang digunakan merujuk kepada perhitungan yang dilakukan oleh Baxter, dkk [15]. Metode yang digunakan adalah metode Baseline dengan parameter yang digunakan adalah perbandingan antara absorban pada $v=1650 \mathrm{~cm}^{-1}$ (serapan gugus amida) dengan absorban pada $v=3450 \mathrm{~cm}^{-}$ ${ }^{1}$ (serapan gugus hidroksi).

$$
\% \mathrm{~N} \text {-deasetilasi }=\left\{100-\left[\left(\frac{A_{1650}}{A_{8450}}\right) \times \frac{100}{1,33}\right]\right\} \%
$$

(Persamaan 1) 
Nilai 1,33 merupakan nilai perbandingan absorban pada $v=1650 \mathrm{~cm}^{-1}$ dan $v=3450 \mathrm{~cm}^{-1}$ untuk N-deasetilasi kitin sempurna. Dari rumus tersebut, diketahui nilai persen derajat deasetilasi kitosan sebesar $71,57 \%$. Hal ini menunjukkan bahwa kitosan komersil yang digunakan pada penelitian ini bisa dikatakan sebagai senyawa kitosan karena nilai derajat deasetilasinya sudah lebih dari $60 \%$ berdasarkan hasil penelitian yang dilakukan oleh Rinaudo, dkk [3].

\subsection{Sintesis Lignin-Kitosan}

Sintesis senyawa lignin-kitosan dilakukan mengikuti metode reaksi Mannich. Persamaan reaksi dapat terlihat di dalam Gambar 1.

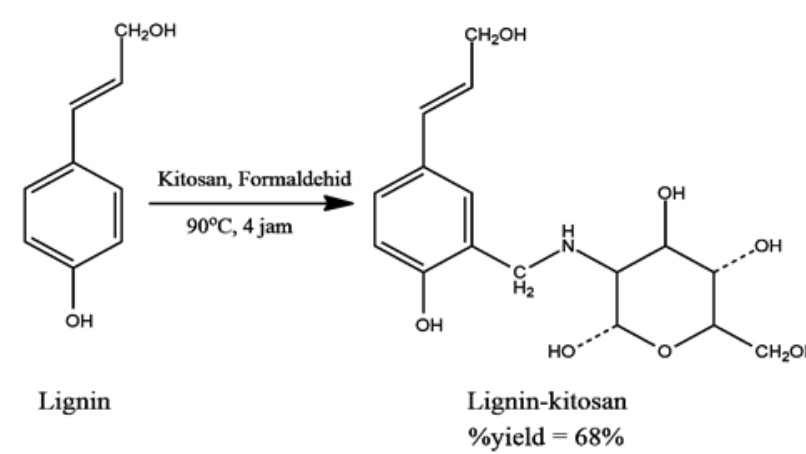

Gambar 1. Persamaan Reaksi Sintesis LigninKitosan

Penggunaan larutan $\mathrm{NaOH}$ pada sintesis ini bertujuan untuk menaikkan $\mathrm{pH}$ sehingga tercipta kondisi basa. Pembuatan kondisi basa tersebut bertujuan untuk menjaga kereaktifan dari gugus amina yang terdapat pada kitosan, sehingga laju reaksi dapat berjalan lebih cepat. Jika reaksi berjalan dalam kondisi asam, maka amina akan terprotonasi dan berubah menjadi amonia. Pembentukan amonia ini harus dihindari dikarenakan amonia memiliki kereaktifan yang lemah, sehingga akan menurunkan laju reaksi pada saat reaksi sintesis dilakukan.

Reaksi sintesis dilakukan menggunakan metode refluks. Setelah refluks selesai dilakukan, larutan didinginkan hingga suhu ruang dan diberi $\mathrm{H}_{2} \mathrm{SO}_{4}$ untuk menurunkan $\mathrm{pH}$ menjadi 2. Hal ini dilakukan untuk mengendapkan lignin-kitosan yang masih dalam bentuk larutan, sehingga endapan tersebut dapat disaring dan dikeringkan di dalam oven selama 12 jam dengan suhu $55^{\circ} \mathrm{C}$. Reaksi aminasi Mannich adalah reaksi alkilasi amina dengan adisi nukleofilik amina ke dalam gugus karbonil menggunakan dua langkah reaksi. Amina pada kitosan yang bersifat nukleofilik dapat menyerang gugus karbonil yang bersifat elektrofilik pada kerangka formaldehid, yang dilanjutkan dengan adanya penstabilan atom $\mathrm{O}$ membentuk gugus alcohol. Selanjutnya pada senyawa 2 menunjukkan alkohol mengikat $\mathrm{H}^{+}$ yang membuatnya menjadi kelebihan muatan, lalu sepasang elektron pada atom $\mathrm{N}$ akan membentuk ikatan baru yang menyebabkan terjadinya pelepasan ikatan $\mathrm{H}_{2} \mathrm{O}$ atau dehidrasi pada reaksi ke 3. Hal ini menyebabkan terbentuknya ion iminium. Tebentuknya ion iminium menyebaban nukleofilik pada gugus fenolik hidroksil menyerang sisi elektrofiliknya yang digambarkan pada nomor 4, sehingga terbentuklah ikatan baru seperti yang ditunjukkan pada senyawa $\mathbf{5}$.

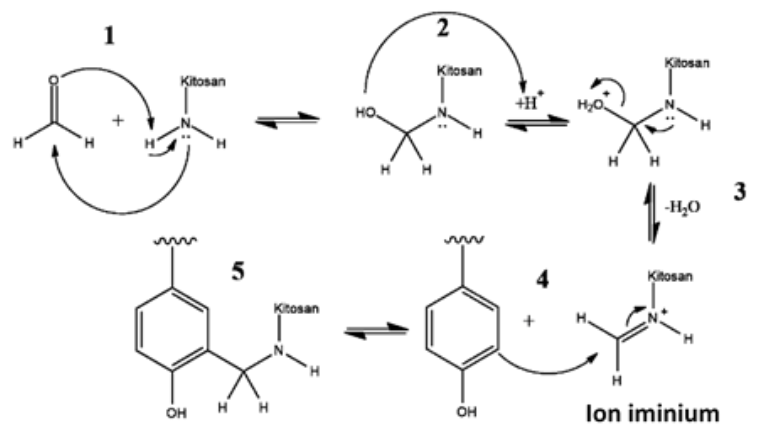

Gambar 2. Usulan Mekanisme Reaksi Mannich pada Sintesis Lignin-kitosan.

\subsection{Hasil Karakterisasi Lignin-Kitosan Menggunakan FTIR}

Pada karakterisasi FTIR, sampel lignin, kitosan, dan lignin-kitosan hasil sintesis menggunakan metode pelet $\mathrm{KBr}$. Tujuan dari karakterisasi ini ialah untuk dapat mengetahui bentuk-bentuk ikatan yang terdapat pada senyawa lignin dan kitosan melalui vibrasi yang yang muncul serta mengetahui apakah reaksi aminasi dengan metode Mannich ini akan berhasil dilakukan. Berikut adalah perbandingan spektrum antara kitosan komersil, lignin serta lignin-kitosan hasil sintesis.

Dari spektrum antara kitosan dan ligninkitosan terlihat penurunan intensitas pada frekuensi $3300-3500 \mathrm{~cm}^{-1}$ yang mengindikasikan adanya penurunan jumlah ikatan $\mathrm{N}-\mathrm{H}$. Hal ini dapat dijelaskan dengan bentuk amina yang dimiliki oleh kedua senyawa tersebut. Pada kitosan, terdapat struktur amina primer (R-NH2) yang memiliki jumlah ikatan $\mathrm{N}-\mathrm{H}$ yang lebih banyak dibandingkan amina sekunder (R-NH-R) yang terdapat pada struktur lignin-kitosan, sehingga dapat disimpulkan bahwa kitosan sudah membentuk ikatan pada lignin. Kemudian dapat dilihat juga terjadi penurunan intensitas pada 
frekuensi $3000-3100 \mathrm{~cm}^{-1}$ dan $3200-3600 \mathrm{~cm}^{-1}$ yang mengindikasikan adanya ikatan $\mathrm{CH}$ aromatik dan alkohol dari spektrum lignin dan ligninkitosan. Hal ini dapat menjelaskan posisi ikatan amina pada bagian lignin. Pada frekuensi $1630-$ $1680 \mathrm{~cm}^{-1}$ terdapat ikatan $\mathrm{C}=\mathrm{O}$ asetamida pada kitosan, hal ini terjadi karena tingkat derajat deasetilasi kitosan hanya mencapai $71,57 \%$ yang artinya masih terdapat gugus asetil pada kitosan komersil yang digunakan. Dari hasil tersebut, spektrum FTIR ini dapat digunakan untuk mengetahui adanya ikatan amina pada lignin.

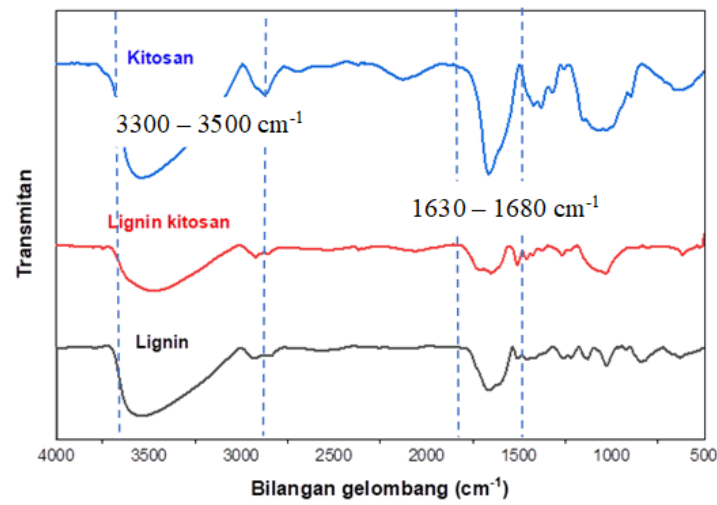

Gambar 3. Perbandingan Spektrum FTIR

Senyawa Kitosan, Lignin, dan Lignin-kitosan

\subsection{Hasil Karakterisasi TGA}

Karakterisasi sampel lignin-kitosan menggunakan TGA bertujuan untuk mengetahui sifat termal degradasi dari sampel tersebut. Pengujiannya dilakukan dengan cara memasukkan $5 \mathrm{mg}$ sampel kedalam wadah yang terbuat dari platinum. Pengukuran yang digunakan pada karakterisasi ini ialah pengukuran dinamis, yaitu pengukuran dengan laju pemanasan yang konstan $\left(5^{\circ} \mathrm{C} /\right.$ menit $)$ dengan suhu maksimal yang digunakan adalah $800^{\circ} \mathrm{C}$. Hasil dari karakterisasi TGA disajikan dalam bentuk kurva pada Gambar 4.

Gambar 4 memperlihatkan bahwa ketiga sampel sudah terdegradasi sebanyak hampir $10 \%$ pada suhu sekitar $100^{\circ} \mathrm{C}$ yang mengindikasikan menguapnya air pada suhu tersebut. Pada suhu $200^{\circ} \mathrm{C}$, lignin-kitosan mengalami degradasi yang diakibat oleh hilangnya gugus karboksil, sedangkan pada lignin mengalami degradasi karena menguapnya fenolik hidroksil dari kerangka strukturnya. Pada kitosan, terjadi degradasi pada suhu $250^{\circ} \mathrm{C}$ yang disebabkan hilangnya gugus karboksil pada struktur tersebut. Ketika suhu sudah mencapai $800^{\circ} \mathrm{C}$, ketiga senyawa tersebut masih memiliki sejumlah \% massa yang tidak terdegradasi seperti lignin $46 \%$, kitosan 27\%, dan lignin-kitosan 36\%. Sisa \% massa lignin-kitosan lebih banyak 9\% dibandingkan kitosan dan lebih sedikit $10 \%$ dari lignin. Hal ini mengindikasikan bahwa ligninkitosan memiliki sifat degradasi termal yang lebih baik dari kitosan. Adanya perbedaan bentuk kurva dari ketiga senyawa tersebut menandakan bahwa lignin-kitosan merupakan produk baru dengan sifat termal yang berbeda berada di antara dua bahan penyusunnya.

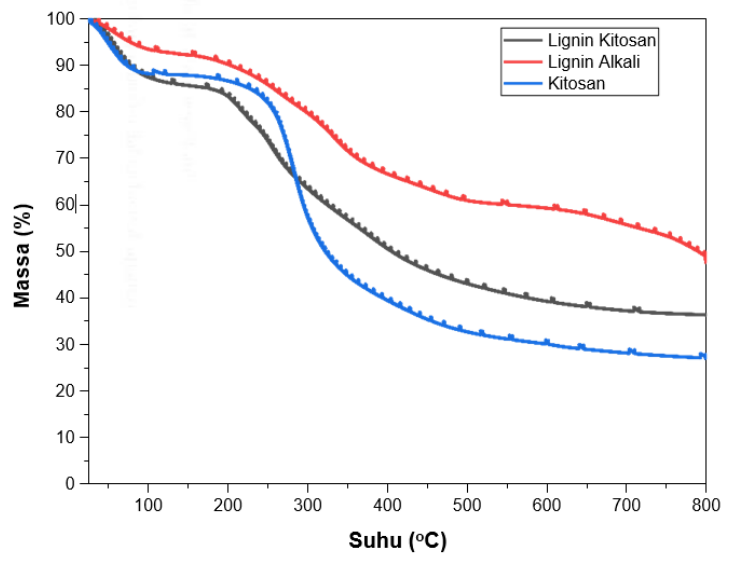

Gambar 4. Kurva TGA Sampel Lignin, Kitosan, dan Lignin-kitosan

\section{Kesimpulan}

Sintesis Lignin-kitosan telah berhasil dilakukan melalui metode Mannich dengan rendemen 68\%. Keberhasilan sintesis ini didukung oleh hasil karakterisasi yaitu FTIR yang menunjukkan berkurangnya intensitas vibrasi $\mathrm{N}$ $\mathrm{H}$ pada daerah $3300 \mathrm{~cm}^{-1}$. Selain itu, analisis TGA menunjukkan bahwa senyawa lignin-kitosan memiliki sifat degradasi termal yang lebih baik dibandingkan kitosan.

\section{Ucapan Terima Kasih}

Terima kasih kepada pihak-pihak terkait di Laboratorium Integrasi Universitas Pertamina atas bantuannya dalam menganalisis hasil sintesis.

\section{Daftar Pustaka}

[1] Gupta KC, Ravi Kumar Mn V. An Overview on Chitin and Chitosan Applications with an Emphasis on Controlled Drug Release Formulations. $J$ Macromol Sci Part C Polym Rev. 2000. 40(4):273-308.

http://dx.doi.org/10.1081/mc-100102399

[2] Dutta PK, Dutta J, Tripathi VS. Chitin and Chitosan: Chemistry, Properties, and Applications. J Sci Ind Res. 2004. 63(1):2031. 
[3] Rinaudo M. Chitin and chitosan: Properties and applications. Prog Polym Sci. 2006. 31(7):603-32.

http://dx.doi.org/10.1016/j.progpolymsci.2 006.06.001

[4] Upton BM, Kasko AM. Strategies for the Conversion of Lignin to High-Value Polymeric Materials: Review and Perspective. Chem Rev. 2015. 116(4):2275306.

http://dx.doi.org/10.1021/acs.chemrev.5b0 0345

[5] Lora JH, Glasser WG. Recent industrial applications of lignin: a suistainable alternative to non-renewable materials. $J$ Polym Environ. 2002. 10(1/2):39-48. http://dx.doi.org/10.1023/a:102107000689 5

[6] Zhang J, Chen Y, Sewell P, Brook MA. Utilization of softwood lignin as both crosslinker and reinforcing agent in silicone elastomers. Green Chem. 2015. 17(3):1811-9.

http://dx.doi.org/10.1039/c4gc02409e

[7] Brodin I, Ernstsson M, Gellerstedt G, Sjöholm E. Oxidative stabilisation of kraft lignin for carbon fibre production. Holzforschung. $2012 . \quad$ 66(2). http://dx.doi.org/10.1515/hf.2011.133

[8] Rodríguez Correa C, Stollovsky M, Hehr T, Rauscher Y, Rolli B, Kruse A. Influence of the Carbonization Process on Activated Carbon Properties from Lignin and LigninRich Biomasses. ACS Sustain Chem Eng. 2017. 5(9):8222-33. http://dx.doi.org/10.1021/acssuschemeng.7 b01895

[9] Calvo-Flores FG, Dobado JA, Isac-García J, Martín-MartíNez FJ. Lignin and Lignans as Renewable Raw Materials [Internet]. John Wiley \& Sons, Ltd; 2015. http://dx.doi.org/10.1002/9781118682784
[10] Li C, Zhao X, Wang A, Huber GW, Zhang T. Catalytic Transformation of Lignin for the Production of Chemicals and Fuels. Chem Rev. 2015. 115(21):11559-624. http://dx.doi.org/10.1021/acs.chemrev.5b0 0155

[11] Zhang J, Ge Y, Qin L, Huang W, Li Z. Synthesis of a lignin-based surfactant through amination, sulfonation, and acylation. J Dispers Sci Technol. 2017. 39(8):1140-3.

http://dx.doi.org/10.1080/01932691.2017.1 385478

[12] Robinson R. LXIII.-A synthesis of tropinone. J Chem Soc, Trans. 1917. 111(0):762-8. http://dx.doi.org/10.1039/ct9171100762

[13] Mannich C, Krösche W. Ueber ein Kondensationsprodukt aus Formaldehyd, Ammoniak und Antipyrin. Arch Pharm (Weinheim). 1912. 250(1):647-67. http://dx.doi.org/10.1002/ardp.1912250015 1

[14] Nair V, Panigrahy A, Vinu R. Development of novel chitosan-lignin composites for adsorption of dyes and metal ions from wastewater. Chem Eng J. 2014. 254:491502. http://dx.doi.org/10.1016/j.cej.2014.05.045

[15] Baxter A, Dillon M, Anthony Taylor KD, Roberts GAF. Improved method for i.r. determination of the degree of $\mathrm{N}$ acetylation of chitosan. Int $J$ Biol Macromol. $1992 . \quad 14(3): 166-9$. http://dx.doi.org/10.1016/s01418130(05)80007-8 